\title{
Discriminant validity of the CAST instrument compared to the dmf index in the deciduous dentition: a cross sectional study
}

Laís Anschau PAULI(a)

Vanessa Polina Pereira da COSTA(a)

Marina Souza AZEVEDO(a) (iD

Soraya Coelho LEAL ${ }^{(b)}$

Marília Leão GOETTEMS(a)

(a) Universidade Federal de Pelotas - UFPel, School of Dentistry, Post-Graduate Program in Dentistry, Pelotas, RS, Brazil.

(b) Universidade de Brasília - UnB, School of Health Sciences, Department of Dentistry, Brasília, DF, Brazil.

Declaration of Interests: The authors certify that they have no commercial or associative interest that represents a conflict of interest in connection with the manuscript.

Corresponding Author:

Marília Leão Goettems

E-mail:mariliagoettems@hotmail.com

Submitted: May 4, 2020

Accepted for publication: October 30, 2020

Last revision: March 2, 2020
Abstract: This study aimed to assess the discriminant validity of the Caries Assessment Spectrum and Treatment (CAST) at different thresholds, compared with the Decayed, Missing, and Filled Teeth Index (dmf) instrument, to discriminate caries risk factors. A cross-sectional study was conducted including children aged 2-5 years from preschools in Southern Brazil. Parents answered a questionnaire, and children were clinically examined using the CAST instrument and, in the following weeks, using the $\mathrm{dmf}$ index. Two caries thresholds were adopted for CAST: caries in dentin $\left(\mathrm{CAST}_{4-7} / \mathrm{CAST}_{2,4-8}\right)$ and enamel caries $\left(\mathrm{CAST}_{3-7} / \mathrm{CAST}_{2-8}\right)$. Poisson regression was used in the analysis $(p<0.05)$. A total of 200 children were included. The prevalence of caries was $47.0 \%$ with dmf, $42.5 \%$ with $\mathrm{CAST}_{4-7}$, and $77.5 \%$ with $\mathrm{CAST}_{3-7}$. When the outcome was caries prevalence, $\mathrm{CAST}_{4-7}$ discriminated between sexes, household crowding, and dental pain, and $\mathrm{CAST}_{3-7}$ discriminated age and family income, while the $\mathrm{dmf}$ was associated with dental pain. When experience of caries was the outcome, all the criteria discriminated between sexes, age, family income, household overcrowding, visible dental plaque, and dental pain, while dmf and $\mathrm{CAST}_{2-8}$ also discriminated maternal schooling. The CAST discriminated caries risk factors similar to the $\mathrm{dmf}$ index when caries experience was the outcome. When prevalence was considered, CAST was able to discriminate for more individual characteristics than $\mathrm{dmf}$.

Keywords: Cross-Sectional Studies; Dental Caries; Diagnosis; Epidemiology; Child.

\section{Introduction}

Dental caries affects children globally, resulting in a major public health problem. ${ }^{1}$ Knowledge about the prevalence of a disease and associated factors is important for planning strategies to control $\mathrm{it}^{2}{ }^{2}$ requiring ongoing assessments of the disease status. Different instruments for assessing dental caries have been described in the literature. ${ }^{3,4,5,6}$ Overall, they differ in the determination of the different stages of caries progression. ${ }^{7}$ The Index of Carious, Missing, and Filled Teeth (dmf/DMF) is the instrument recommended by the World Health Organization $(\mathrm{WHO})^{4}$ and has been 
widely used in studies worldwide. This index is intended for the detection of dental caries when there is obvious cavitation, and restored and lost teeth are also accounted for determining the prevalence of dental caries.

More recently, the Caries Assessment Spectrum Treatment (CAST) instrument has been developed to evaluate the entire progression of caries disease. ${ }^{7}$ This instrument detects the initial lesions on the enamel till the pulp involvement, the presence of an abscess or fistula and allows the adoption of different thresholds to report the prevalence of dental caries. Sealed, restored, and lost teeth due to caries are also evaluated; however, based on the rationale of the instrument, they are not accounted for determining the disease prevalence. ${ }^{6}$

Using a conversion criterion proposed by the authors of the CAST instrument, ${ }^{6}$ this system presented results similar to those obtained by the $\mathrm{DMF} / \mathrm{dmf}$ index for prevalence and experience of dental caries. ${ }^{89,10}$ However, the threshold for the disease where CAST has a better ability to discriminate distinct subgroups is unknown. Additionally, to date, no study has compared the discriminant capacity of the CAST instrument at different thresholds for dental caries with the discriminant validity of the $\mathrm{dmf}$ index. Assessment of the CAST ability to discriminate dental caries risk factors at different thresholds is important for determining the discriminatory power of the instrument.

In addition, it is not clear whether the inclusion of early stage carious lesions influence association with the risk indicators for the disease. Studies using the International Caries Detection and Assessment System (ICDAS) illustrate that this more recent index can discriminate among groups of children and adults with different exposure to risk factors. ${ }^{11}$ Mendes et al. ${ }^{12}$ have investigated the discriminatory power of the ICDAS compared to the WHO standard criteria and found that cavitated scores of ICDAS present similar discriminant validity compared with $\mathrm{dmf}$ criteria when the presence of caries is used as an outcome; however, the index loses discriminatory power when non-cavitated caries is included. When $\mathrm{dmfs}$ values are used, no differences are observed in the use of non-cavitated or cavitated carious lesions. According to the authors ${ }^{12}$ this issue should be addressed in further studies owing to variable results in populations with different prevalence of dental caries.

Thus, the discriminant validity of CAST compared with $\mathrm{dmf}$ in primary dentition has not been evaluated, and investigating this characteristic is important to appraise the comprehensiveness of the method. ${ }^{12}$ Therefore, this study aimed to determine the ability of the CAST instrument to discriminate socioeconomic, demographic, and clinical factors associated with the onset of dental caries at different thresholds in a sample of preschool children, and to compare it with the discriminatory power of the $\mathrm{dmf}$ index. The hypothesis was that the CAST instrument, at all thresholds, would be able to discriminate subgroups and that CAST and $\mathrm{dmf}$ would have similar discriminating ability.

\section{Methodology}

This study was reported using Strengthening the Reporting of Observational Studies in Epidemiology (STROBE). ${ }^{13}$

\section{Study design and sample population}

This is a cross-sectional school-based study, conducted with children aged 2-5 years enrolled in pre-schools of the municipality of Capão do Leão, South Brazil. According to data from the last demographic census, the city has 24,928 inhabitants, with 2,280 aged $0-5$ years.

The city has three public schools that serve the age group of the study and do not have private schools. A total of 267 preschoolers aged 2-5 years were enrolled in schools in 2018 and were initially considered eligible to participate in the study. A minimum sample size of 153 children was predicted to detect a prevalence of $39 \%$ of dental caries in preschool children ${ }^{14}$ considering a $95 \%$ confidence level. Children with physical or psychological disabilities that made the examination impossible were excluded.

This study was approved by the local Municipal Secretary of Education and by the local Human Research Ethics Committee under protocol 2.531.245. 
The legal guardians were informed about the study, and they signed a consent form to authorize the use of the data and child's participation in the research. Additionally, children who did not allow and/or did not cooperate with the oral examination were not included, although they could participate. The CAST instrument and the $\mathrm{dmf}$ index were designed for use in epidemiological research, assisting in the planning of oral health services. Thus, parents received written information about their children's oral health according to the results of the epidemiological examination and were oriented for carrying out a more comprehensive assessment in a dental office, for which the contacts of the School of Dentistry were made available. Preschoolers were given toothbrushes, and they participated in oral health education activities, including oral hygiene instructions; children with pain or infection were referred to the School of Dentistry for treatment.

\section{Data collection}

Family demographic, socioeconomic, and dental pain data were collected through a questionnaire sent to parents or legal guardians through the school. The child's age was collected in years and dichotomized (2-3 years/4-5 years). Maternal schooling was collected in terms of years of study and categorized into two groups ( $<8$ years $/ \geq 8$ years). The monthly income was collected in Brazilian Reais and dichotomized by the median up to 1.5 Brazilian minimum wage and greater than 1.5 Brazilian minimum wage $(\leq 1.5$ BMW/>1.5 BMW). Parents were also questioned about the number of people living in the house $(\leq 4 />4)$. Pain was assessed by asking the parents about the occurrence of dental pain in their son/daughter in the last 6 months and dichotomized into yes (present) and no (absent). ${ }^{15}$

The oral examinations were carried out between May and August, 2018 at the school's facilities, by two previously trained and calibrated postgraduate students. The presence of visible plaque was collected following the criteria of Alaluusua and Malmivirta, ${ }^{16}$ which suggested visual inspection of the vestibular surfaces of the upper central incisors and dichotomized into yes (presence of plaque) and no (absence of visible plaque).
Dental caries was initially evaluated by the CAST instrument, and in the following weeks, the children were reevaluated for dental caries using the $\mathrm{dmf}$ index. The CAST instrument is composed of 10 codes classified hierarchically: 0 : healthy; 1 : sealant; 2: restoration; 3 : distinct visual change only in the enamel; 4: discoloration related to internal caries in the dentin; 5: distinct cavitation in dentin; 6: involvement of the pulp chamber; 7 : abscess / fistula; 8 : lost by caries; and 9: none of the previous descriptions. ${ }^{7}$ Using the $\mathrm{dmf}$ index, the surfaces were recorded as sound, decayed, missing, or filled. Caries were recorded when it had evident cavity, unsupported enamel, or detectably softened bottom or wall. ${ }^{4}$

The examinations with both instruments were performed on the school premises, with the children in the supine position, chin up on school tables, using artificial lighting (study lamp), clinical mirror, and, the Community Periodontal Index probe, if required. After registering the visible plaque, the dental surfaces were cleaned with a toothbrush and excess moisture was removed with gauze and/or cotton swabs. The examinations were typed directly into a specific form using the Microsoft Office Excel program.

Schools were visited until no more than $10 \%$ of the children were absent from the oral examination using CAST. For evaluation using the $\mathrm{dmf}$ index, the same examiners visited the classes at least twice.

\section{Training and calibration methods}

For use of the CAST, the researchers participated in theoretical and practical training (12 hours) with the authors of the CAST instrument. A new theoretical and practical training using the material provided by the instrument developers was carried. The theoretical training (4 hours) included the presentation of the guidelines and structure of the instrument, its codes and descriptors, protocol and manner of conducting the exam, and photographs illustrating the clinical situations covered by the instrument. In practical training (4 hours), photographs and extracted teeth were examined, and disagreements were discussed.

Training for the use of the $\mathrm{dmf}$ index was also conducted with the study examiners. This included a theoretical stage (4 hours), where the instrument 
structure, its codes and descriptors were presented, and a practical stage (4 hours), with the examination of photographs and extracted teeth, followed by discussion of the disagreements.

After the training, calibration was performed for both instruments. A sample of 10 children of the same age group and socioeconomic status of the main study was preselected. The first examinations were discussed together between the study examiners and the experienced examiner. Afterwards, 20 children were individually examined by each examiner and the values obtained were compared to those of the experienced examiner to ensure inter-examiner agreement. The weighted kappa coefficient $(\mathrm{k})$ was 0.68 and 0.72 (CAST), and 0.96 and 0.92 (dmf) and the agreement percentage (Po) was $96.2 \%$ and $97.0 \%$ for the CAST instrument and $99.7 \%$ and $99.3 \%$ for the $\mathrm{dmf}$ index, respectively. For determining the intra-examiner agreement, $10 \%$ of the sample in the main study was reexamined, and both examiners achieved acceptable results. The mean weighted kappa coefficient was 0.71 , with 0.021 standard error (SE) and Po was $97.0 \%$.

\section{Data analysis}

Data of the questionnaires were double-typed, with posterior checking, in the Microsoft Office Excel program. The analyses were conducted using Stata 14.0 software (Stata Corporation, College Station, USA). Initially, descriptive statistics were made.

The threshold for dental caries was defined according to the concepts of each instrument. CAST uses the health/disease concept and considers surfaces treated with sealants (code 1), restorations (code 2), and extracted teeth (code 8) to be healthy. Therefore, only children who had carious lesions without treatment were counted for the prevalence of caries assessed with CAST. Therefore, CAST codes 1,2 , and 8 were not included in the prevalence of the disease. The prevalence of dental caries obtained by the CAST instrument was then estimated using two different cutoff points, following the concept proposed by the instrument: $\mathrm{CAST}_{4-7}$ included caries in dentin (codes 4-7 were considered caries) and $\mathrm{CAST}_{3-7}$ included enamel caries (codes 3-7 were considered caries). ${ }^{17}$
The caries experience using the CAST was calculated at the dental surface level, and was also obtained from two thresholds, which included untreated illness and previous experience (sealed and restored surfaces and missing teeth), as follows: dentin threshold: CAST $_{2,4-8}$ (codes 2 and 4-8 were included), and enamel threshold: $\mathrm{CAST}_{2-8}$ (codes 2-8 were included $)^{17}$. For the calculation of the prevalence and experience values obtained with the $\mathrm{dmf}$ index, all components $(\mathrm{d} / \mathrm{m} / \mathrm{f})$ were included, as suggested by the instrument. ${ }^{4}$

For determining the discriminant validity of the instruments, the association between the independent variables and the presence of caries was initially assessed using the $\mathrm{dmf}$ index and thresholds for the CAST instrument. The prevalence ratio, confidence interval (95\% CI), and level of significance were obtained using the Poisson regression analysis with robust variance. The experience values obtained using the same thresholds for the CAST and using the $\mathrm{dmf}$ index were also associated with the independent variables to assess discriminant validity. The rate ratio $(95 \%$ CI) and significance levels were obtained using the Poisson regression analysis with robust variance. Analyses were conducted adopting a level of statistical significance defined at $p<0.05$.

\section{Results}

Of the 264 eligible children, 40 (15.1\%) did not return the authorization, 14 (5.3\%) were absent or did not allow the oral examination, and 10 (3.8\%) were absent or no longer attending school in the second stage. The rate of return was $75.8 \%$, and the final sample consisted of 200 children.

Table 1 shows the distribution of children with dental caries classified by the dmf index and the two thresholds for the CAST instrument and demographic, socioeconomic, and clinical variables. The prevalence of dental caries in preschoolers was $47.0 \%$ with the $\mathrm{dmf}$ index, $42.5 \%$ with $\mathrm{CAST}_{4-7}$, and $77.5 \%$ with $\mathrm{CAST}_{3-}$ 7. Caries' experience values (mean $\pm \mathrm{SD}$ ) according to the different instruments and cut-off points and independent variables are presented in Table 2. Higher values were observed for $\mathrm{CAST}_{2-8}$ 
Table 1. Prevalence of caries according to the CAST at thresholds $C A T_{4.7}$ and CAST $_{3.7}$ and to the dmf index and independent variables $(n=200)$.

\begin{tabular}{|c|c|c|c|c|}
\hline \multirow{2}{*}{ Variables } & \multirow{2}{*}{$\mathrm{n}$} & $d m f$ & $\mathrm{CAST}_{4-7}$ & $\mathrm{CAST}_{3-7}$ \\
\hline & & n (\%) & n (\%) & n (\%) \\
\hline \multicolumn{5}{|l|}{ Sex } \\
\hline Female & 99 & $40(40.4)$ & $34(34.3)$ & $74(74.8)$ \\
\hline Male & 101 & $54(53.5)$ & $51(50.5)$ & $81(80.2)$ \\
\hline \multicolumn{5}{|l|}{ Age } \\
\hline $2-3$ years & 29 & $11(37.9)$ & $8(27.6)$ & $16(55.2)$ \\
\hline $4-5$ years & 171 & $83(48.5)$ & $77(45.0)$ & $139(81.3)$ \\
\hline \multicolumn{5}{|c|}{ Maternal education* } \\
\hline$<8$ years & 42 & $23(54.8)$ & $19(45.2)$ & $34(81.0)$ \\
\hline$\geq 8$ years & 149 & $64(43.0)$ & $60(40.3)$ & $113(75.8)$ \\
\hline \multicolumn{5}{|l|}{ Family income* } \\
\hline$>1.5 \mathrm{BMW}$ & 86 & $35(40.7)$ & $31(36.1)$ & $62(72.1)$ \\
\hline$\leq 1.5 \mathrm{BMW}$ & 77 & $43(55.8)$ & $37(48.1)$ & $66(85.7)$ \\
\hline \multicolumn{5}{|c|}{ Number of people living in the house* } \\
\hline$\leq 4$ peoples & 142 & $61(43.0)$ & $52(36.6)$ & $110(77.5)$ \\
\hline$>4$ peoples & 53 & $30(56.6)$ & $30(56.6)$ & $41(77.4)$ \\
\hline \multicolumn{5}{|c|}{ Presence of visible plaque } \\
\hline No & 146 & $65(44.5)$ & $58(39.7)$ & $109(74.7)$ \\
\hline Yes & 54 & $29(53.7)$ & $27(50.0)$ & $46(85.2)$ \\
\hline \multicolumn{5}{|c|}{ Dental pain in the last 6 months } \\
\hline No & 170 & $71(41.7)$ & $63(37.1)$ & $130(76.5)$ \\
\hline Yes & 30 & $23(79.3)$ & $22(75.9)$ & $24(82.8)$ \\
\hline
\end{tabular}

*missing data.

Dental pain was significantly associated with the presence of dental caries, as assessed by the $\mathrm{dmf}$ and $\mathrm{CAST}_{4-7}$. Male sex and household overcrowding were associated with the occurrence of dental caries, as evaluated by the $\mathrm{CAST}_{4-7}$. Age between 4 and 5 years and family income of up to 1.5 Brazilian minimum wage showed a significant association with the occurrence of dental caries, as evaluated by the $\mathrm{CAST}_{3-7}$. Maternal schooling and presence of visible plaque were not associated with the occurrence of dental caries assessed at any instrument (Table 3).

Male sex, age between 4 and 5 years, family income of up to 1.5 Brazilian minimum wage, household overcrowding, presence of visible plaque, and dental pain were significantly associated with caries experience, regardless of the criteria adopted
(Table 4). Lower maternal schooling was significantly associated with caries experience when $\mathrm{dmf}$ and $\mathrm{CAST}_{2-8}$ were the criteria used.

\section{Discussion}

This study has investigated a representative sample of preschool children using the dmf index, which is the most used instrument worldwide, compared with the CAST instrument, to determine caries prevalence and experience and to evaluate the discriminant validity of CAST in primary dentition, compared with dmf. The CAST instrument uses the epidemiological concept of health and disease and is not included in the prevalence of the disease, treated surfaces with sealants, restorations, and extracted teeth. ${ }^{17}$ In this study, when comparing the prevalence 
Discriminant validity of the CAST instrument compared to the dmf index in the deciduous dentition: a cross sectional study

Table 2. Caries experience (mean \pm SD) according to the CAST at thresholds CAST $_{2,4-8}$ and CAST $_{2-8}$ and to the dmf index and independent variables $(\mathrm{n}=200)$.

\begin{tabular}{|c|c|c|c|}
\hline Variables & $d m f$ & $\mathrm{CAST}_{2,4-8}$ & $\mathrm{CAST}_{2-8}$ \\
\hline \multicolumn{4}{|l|}{ Sex } \\
\hline Female & $3.31 \pm 7.92$ & $2.78 \pm 6.41$ & $8.67 \pm 10.31$ \\
\hline Male & $4.47 \pm 8.40$ & $3.81 \pm 6.70$ & $9.50 \pm 9.33$ \\
\hline \multicolumn{4}{|l|}{ Age } \\
\hline $2-3$ years & $1.93 \pm 4.50$ & $1.38 \pm 3.71$ & $3.31 \pm 5.28$ \\
\hline $4-5$ years & $4.22 \pm 8.60$ & $3.63 \pm 6.89$ & $7.99 \pm 9.67$ \\
\hline \multicolumn{4}{|c|}{ Maternal education* } \\
\hline$<8$ years & $4.24 \pm 6.62$ & $3.57 \pm 5.60$ & $8.10 \pm 8.23$ \\
\hline$\geq 8$ years & $3.46 \pm 8.45$ & $3.01 \pm 6.72$ & $6.87 \pm 9.55$ \\
\hline \multicolumn{4}{|l|}{ Family income* } \\
\hline$>1.5 \mathrm{BMW}$ & $2.40 \pm 4.76$ & $2.17 \pm 4.34$ & $5.92 \pm 7.61$ \\
\hline$\leq 1.5 \mathrm{BMW}$ & $5.96 \pm 11.21$ & $4.96 \pm 8.87$ & $9.34 \pm 11.27$ \\
\hline \multicolumn{4}{|c|}{ Number of people living in the house* } \\
\hline$\leq 4$ peoples & $3.11 \pm 7.00$ & $2.56 \pm 5.87$ & $6.18 \pm 8.12$ \\
\hline$>4$ peoples & $6.19 \pm 10.69$ & $5.43 \pm 8.05$ & $10.57 \pm 11.62$ \\
\hline \multicolumn{4}{|c|}{ Presence of visible plaque } \\
\hline No & $3.21 \pm 7.14$ & $2.70 \pm 5.97$ & $5.96 \pm 8.08$ \\
\hline Yes & $5.74 \pm 10.30$ & $4.93 \pm 7.78$ & $10.96 \pm 11.29$ \\
\hline \multicolumn{4}{|c|}{ Dental pain in the last 6 months } \\
\hline No & $1.29 \pm 4.46$ & $1.75 \pm 3.41$ & $5.54 \pm 7.02$ \\
\hline Yes & $12.5 \pm 15.33$ & $10.93 \pm 11.92$ & $16.35 \pm 13.64$ \\
\hline
\end{tabular}

*missing data.

Table 3. Prevalence ratio values $(95 \% \mathrm{Cl})$ calculated by Poisson regression, using children with caries as the outcome according to CAST at thresholds CAST . $_{47}$ and $\mathrm{CAST}_{3.7}$ and to the $\mathrm{dmf}$ index and independent variables $(\mathrm{n}=200)$.

\begin{tabular}{|c|c|c|c|}
\hline Variables & dmf & $\mathrm{CAST}_{4-7}$ & $\mathrm{CAST}_{3-7}$ \\
\hline \multicolumn{4}{|l|}{ Sex (ref.: female) } \\
\hline Male & $\begin{array}{c}1.32(0.98-1.79) \\
p=0.068\end{array}$ & $\begin{array}{c}1.47(1.05-2.05) \\
p=0.024\end{array}$ & $\begin{array}{c}1.07(0.92-1.25) \\
p=0.359\end{array}$ \\
\hline \multicolumn{4}{|c|}{ Age (ref.: 2-3 years) } \\
\hline $4-5$ years & $\begin{array}{c}1.28(0.78-2.09) \\
p=0.326\end{array}$ & $\begin{array}{c}1.63(0.88-3.02) \\
p=0.118\end{array}$ & $\begin{array}{c}1.47(1.05-2.06) \\
p=0.024\end{array}$ \\
\hline \multicolumn{4}{|c|}{ Maternal education* (ref.: $<8$ years) } \\
\hline$\geq 8$ years & $\begin{array}{c}0.78(0.56-1.09) \\
p=0.152\end{array}$ & $\begin{array}{c}0.89(0.60-1.31) \\
p=0.556\end{array}$ & $\begin{array}{c}0.94(0.79-1.11) \\
p=0.459\end{array}$ \\
\hline \multicolumn{4}{|c|}{ Family income* (ref.: > 1.5 BMW) } \\
\hline$\leq 1.5 \mathrm{BMW}$ & $\begin{array}{c}1.37(0.99-1.90) \\
p=0.056\end{array}$ & $\begin{array}{c}1.33(0.92-1.92) \\
p=0.124\end{array}$ & $\begin{array}{c}1.19(1.01-1.40) \\
p=0.035\end{array}$ \\
\hline \multicolumn{4}{|c|}{ Number of people living in the house ${ }^{*}$ (ref.: $\leq 4$ peoples) } \\
\hline$>4$ people & $\begin{array}{c}1.31(0.97-1.78) \\
p=0.075\end{array}$ & $\begin{array}{c}1.55(1.12-2.13) \\
p=0.008\end{array}$ & $\begin{array}{c}1.00(0.84-1.18) \\
p=0.987\end{array}$ \\
\hline \multicolumn{4}{|c|}{ Presence of visible plaque (ref.: No) } \\
\hline Yes & $\begin{array}{c}1.21(0.89-1.64) \\
p=0.232\end{array}$ & $\begin{array}{c}1.26(0.90-1.76) \\
p=0.177\end{array}$ & $\begin{array}{c}1.14(0.99-1.32) \\
p=0.077\end{array}$ \\
\hline \multicolumn{4}{|c|}{ Dental pain in the last 6 months (ref.: No) } \\
\hline Yes & $\begin{array}{c}1.18(1.09-1.28) \\
p<0.001\end{array}$ & $\begin{array}{c}1.19(1.09-1.29) \\
p<0.001\end{array}$ & $\begin{array}{c}1.04(0.94-1.15) \\
p=0.423\end{array}$ \\
\hline
\end{tabular}

*missing data. 
Table 4. Rate ratio values $(95 \% \mathrm{Cl})$ calculated by Poisson regression using experience values as the outcome according to the CAST at thresholds $\mathrm{CAST}_{2,4-8}$ and $\mathrm{CAST}_{2-8}$ and to the $\mathrm{dmf}$ index and independent variables $(\mathrm{n}=200)$.

\begin{tabular}{|c|c|c|c|}
\hline Variables & dmf & $\mathrm{CAST}_{2,4-8}$ & $\mathrm{CAST}_{2-8}$ \\
\hline \multicolumn{4}{|l|}{ Sex (ref.: female) } \\
\hline \multirow{2}{*}{ Male } & $1.35(1.17-1.55)$ & $1.37(1.18-1.60)$ & $1.25(1.13-1.38)$ \\
\hline & $p<0.001$ & $p<0.001$ & $p<0.001$ \\
\hline \multicolumn{4}{|c|}{ Age (ref.: 2-3 years) } \\
\hline \multirow{2}{*}{$4-5$ years } & $2.19(1.67-2.87)$ & $2.63(1.91-3.62)$ & $2.41(1.96-2.97)$ \\
\hline & $p<0.001$ & $p<0.001$ & $p<0.001$ \\
\hline \multicolumn{4}{|c|}{ Maternal education* (ref.: $<8$ years) } \\
\hline \multirow{2}{*}{$\geq 8$ years } & $0.82(0.69-0.97)$ & $0.84(0.70-1.01)$ & $0.85(0.75-0.96)$ \\
\hline & $p=0.020$ & $p=0.068$ & $p=0.009$ \\
\hline \multicolumn{4}{|c|}{ Family income* (ref.: > 1,5 BMW) } \\
\hline \multirow{2}{*}{$\leq 1,5 \mathrm{BMW}$} & $2.49(2.11-2.93)$ & $2.28(1.92-2.72)$ & $1.58(1.41-1.77)$ \\
\hline & $p<0.001$ & $p<0.001$ & $p<0.001$ \\
\hline \multicolumn{4}{|c|}{ Number of people in the house* $($ ref.: $\leq 4)$} \\
\hline \multirow{2}{*}{$>4$ peoples } & $1.99(1.73-2.30)$ & $2.13(1.82-2.48)$ & $1.71(1.54-1.90)$ \\
\hline & $p<0.001$ & $p<0.001$ & $p<0.001$ \\
\hline \multicolumn{4}{|c|}{ Presence of visible plaque (ref.: No) } \\
\hline \multirow{2}{*}{ Yes } & $1.79(1.55-2.06)$ & $1.83(1.56-2.13)$ & $1.84(1.66-2.04)$ \\
\hline & $p<0.001$ & $p<0.001$ & $p<0.001$ \\
\hline \multicolumn{4}{|c|}{ Dental pain in the last 6 months (ref.: No) } \\
\hline \multirow{2}{*}{ Yes } & $5.72(3.41-9.62)$ & $6.23(3.88-10.02)$ & $2.95(2.09-4.16)$ \\
\hline & $p<0.001$ & $p<0.001$ & $p<0.001$ \\
\hline
\end{tabular}

*missing data.

of dental caries using the $\mathrm{dmf}$ and $\mathrm{CAST}_{4-7}$, the results were similar, despite $\mathrm{dmf}$ index accounting for restorations and extractions in the prevalence of caries, including past and present disease. Although $\mathrm{dmf}$ could overestimate the prevalence of individuals with the current disease and untreated, only a few children in this sample had these conditions. In the primary dentition, most teeth affected by caries are left untreated, ${ }^{18.19}$ which may justify similar values of prevalence.

Previous experiences of disease are linked to future caries experiences, as restored teeth will need to be replaced (especially among adults) throughout life and, in children with previous caries experience, the risk of developing new lesions is higher compared to children without previous dental caries. ${ }^{20}$ The CAST instrument clearly differentiates past caries experience from caries prevalence, which facilitates the understanding of the history of the disease in a population from the treatment needs that they present when the evaluation takes place. The first data may be helpful in the prediction of future disease, while the second one precisely orientates the severity of the disease and actions that should be taken.

Only slightly more than half of the children in this study were free of dental caries when examined using the $\mathrm{dmf}$ index $(53.0 \%)$ and $\mathrm{CAST}_{4-7}(57.5 \%)$. These results are comparable to the prevalence of caries in Brazilian children ${ }^{20}$ because only $46.6 \%$ of 5 - yearold children were free of the disease. When enamel lesions $\left(\mathrm{CAST}_{3-7}\right)$ were included, only one- fifth of the children were free of caries $(22.5 \%)$, revealing an increase of $35 \%$ in relation to the CAST dentin threshold and $30 \%$ higher compared to dmf. This large increase in prevalence is expected and is in accordance with the previous studies using the CAST, which also reported a larger number of children affected by the disease when enamel lesions were accounted. ${ }^{21}$ The high prevalence of caries in this population reinforces the importance of epidemiological surveys 
investigating the occurrence of dental caries to help establish preventive strategies. Additionally, data on the percentage of children with only enamel lesions is useful for the planning of public health managers as this condition can be easily managed in schools and health services, avoiding the need for more invasive and costly treatments.

When the prevalence of dental caries was used as the outcome, the CAST instrument, at the cutoff points adopted, discriminated more risk factors for dental caries than the $\mathrm{dmf}$ index. Male sex and higher household crowding were associated with caries occurrence with the CAST threshold for dentin caries $\left(\mathrm{CAST}_{4-7}\right)$, while higher age and lower family income were associated with caries occurrence with the enamel caries threshold $\left(\mathrm{CAST}_{3-7}\right)$. The $\mathrm{dmf}$ index and $\mathrm{CAST}_{4-7}$ discriminated for the occurrence of pain. Therefore, in this sample, the CAST instrument, at both cutoff points, was more sensitive in discriminating risk factors for the occurrence of caries than the $\mathrm{dmf}$ index. These results are different from those of a previous study that compared the discriminant validity of the dmf index with different cut- off points of the ICDAS. ${ }^{12}$ In that study, demographic and socioeconomic variables were not associated with ICDAS when non- cavitated lesions were included (ICDAS 2), despite the fact that they were associated with caries diagnosed using $\mathrm{dmf}$ and with ICDAS 3 , including lesions with enamel breakdown. According to the authors, this loss of discriminant capacity with the inclusion of non- cavitated lesions was owing to nearly all children presenting caries when these lesions were included (83.3\%). Therefore, the difference in the results of these studies may have occurred due to the different prevalence of disease stages in the populations studied, in addition to the different criteria used in the diagnosis.

When caries experience was used as outcome, the inclusion of enamel lesions did not change the discriminant validity of the CAST instrument. In fact, some variables that had been associated with the count outcome were not associated with the presence of minimum one lesion. All the adopted criteria discriminated for sex, age, household income, household overcrowding, and visible plaque, and the $\mathrm{dmf}$ and $\mathrm{CAST}_{2-8}$ also discriminated maternal schooling. All these variables are recognized risk factors for the development of dental caries in children. In addition age was associated with increase in dental caries experience. ${ }^{22,23,24}$ The presence of pain was also associated with caries regardless of the criteria used, confirming that the inclusion of enamel lesions did not affect the discriminant validity. A study using CAST to evaluate factors associated with dental caries in children aged 2- 4 years in a city in Tanzania, adopting different cutoff points for CAST also found association with the child's age; however, other demographic and socioeconomic characteristics were not associated with dental caries at any threshold. ${ }^{2}$

One of the advantages of using CAST is that it provides information on enamel caries lesions ${ }^{9,10}$ An increase in the prevalence and experience of early stages of caries with age is an indication that the population is at risk of developing the disease. ${ }^{8}$ In addition, the primary teeth are subject to an accelerated progression of enamel caries to the dentin and later to the pulp, owing to the smaller thickness of the dentin and wider pulp chamber. ${ }^{25}$ In contrast, a study evaluating progression to dentine cavitation in primary dentition has found that the rate of progression of initial non- cavitated caries is low, while that for teeth presenting with cavitated enamel lesions is remarkably high. ${ }^{26}$ The CAST instrument does not differentiate enamel lesions into cavitated or non- cavitated, both being registered under the same code. Thus, we suggest new studies using the CAST, with a longitudinal design and evaluation of the presence or absence of cavitation in the enamel, with analysis of disease progression. The inclusion of initial enamel lesions in oral health surveys can therefore be justified by the knowledge acquired over the last decades on the control of caries initiation and progression ${ }^{27}$ and because the different stages of dental caries may have different associated factors, which has been investigated in this study.

The CAST instrument is a promising tool for international use in epidemiological studies on dental caries. ${ }^{8}$ The results of this study suggest that the instrument can be used in epidemiological surveys intended to assess caries lesions, as it can identify children with increased disease experience. 
This study has the limitation of its cross- sectional design, which does not allow the evaluation of causal relationships between the disease and associated factors. The external and internal validity of the study was ensured, as all preschools in the city were included and dentists were trained and calibrated.

CAST is a useful and practical index in epidemiological surveys, ${ }^{28}$ However as it was more recently developed, the literature lacks studies using this instrument to evaluate factors associated with dental caries in different age groups. Thus, it is difficult to compare these findings, because few studies exist assessing the same age range of our study. ${ }^{2}$ To the best of our knowledge, this is the first study to investigate the discriminatory power of CAST. Therefore, new studies are suggested, with longitudinal design and investigation of the factors associated with the different stages of caries in the primary dentition and in other age groups.

\section{Conclusions}

In the present study, the CAST instrument had the ability to discriminate risk factors for dental caries similar to the dmf index when the caries experience was used as an outcome. When prevalence was considered, CAST was able to discriminate for more individual characteristics than $\mathrm{dmf}$.

\section{Acknowledgments}

This study was financed in part by the Coordenação de Aperfeiçoamento de Pessoal de Nível Superior - Brasil (CAPES) - Finance Code 001. Authors acknowledge CAPES for the MsC scholarship (L.A.P.).

\section{References}

1. Petersen PE. The World Oral Health Report 2003: continuous improvement of oral health in the 21 st century-the approach of the WHO Global Oral Health Programme. Community Dent Oral Epidemiol. 2003 Dec;31 Suppl 1:3-23. https://doi.org/10.1046/j..2003.com122.x

2. Mwakayoka H, Masalu JR, Namakuka Kikwilu E. Dental caries and associated factors in children aged 2-4 years old in Mbeya City, Tanzania. J Dent (Shiraz). 2017 Jun;18(2):104-11.

3. Pitts N. "ICDAS": an international system for caries detection and assessment being developed to facilitate caries epidemiology, research and appropriate clinical management. Community Dent Health. 2004 Sep;21(3):193-8.

4. World Health Organization -WHO. Oral health surveys: basic methods. 5th ed. Geneva: WHO; 2018.

5. Monse B, Heinrich-Weltzien R, Benzian H, Holmgren C, van Palenstein Helderman W. PUFA: an index of clinical consequences of untreated dental caries. Community Dent Oral Epidemiol. 2010 Feb;38(1):77-82. https://doi.org/10.1111/j.1600-0528.2009.00514.x

6. Leal SC, Ribeiro AP, Frencken JE. Caries Assessment Spectrum and Treatment (CAST): a novel epidemiological instrument. Caries Res. 2017;51(5):500-6. https://doi.org/10.1159/000479042

7. Frencken JE, Amorim RG, Faber J, Leal SC. The Caries Assessment Spectrum and Treatment (CAST) index: rational and development. Int Dent J. 2011 Jun;61(3):117-23. https://doi.org/10.1111/j.1875-595X.2011.00022.x

8. Baginska J, Rodakowska E, Kierklo A. Status of occlusal surfaces of first permanent molars in 6-8-year-old children evaluated by the CAST and DMF indices. Eur J Paediatr Dent. 2014 Jun;15(2):107-12.

9. Souza AL, Leal SC, Bronkhorst EM, Frencken JE. Assessing caries status according to the CAST instrument and WHO criterion in epidemiological studies. BMC Oral Health. 2014 Sep;14(1):119. https://doi.org/10.1186/1472-6831-14-119

10. Castro AL, Vianna MI, Mendes CM. Comparison of caries lesion detection methods in epidemiological surveys: CAST, ICDAS and DMF. BMC Oral Health. 2018 Jul;18(1):122. https://doi.org/10.1186/s12903-018-0583-6

11. Ismail Al., Sohn W., Tellez M., Amaya A., Sen A., Hasson H., et al. The International Caries Detection and Assessment System (ICDAS): an integrated system for measuring dental caries: Methods. Community Dent Oral Epidemiol. 2007 May;35(3):170-8. https://doi.org/10.1111/j.1600-0528.2007.00347.x

12. Mendes FM, Braga MM, Oliveira LB, Antunes JL, Ardenghi TM, Bönecker M. Discriminant validity of the International Caries Detection and Assessment System (ICDAS) and comparability with World Health Organization criteria in a cross-sectional study. Community Dent Oral Epidemiol. 2010 Oct;38(5):398-407. https://doi.org/10.1111/j.1600-0528.2010.00557.x 
Discriminant validity of the CAST instrument compared to the dmf index in the deciduous dentition: a cross sectional study

13. von Elm E, Altman DG, Egger M, Pocock SJ, Gøtzsche PC, Vandenbroucke JP; STROBE Initiative. The strengthening the reporting of observational studies in epidemiology (STROBE) statement: guidelines for reporting observational studies. Int J Surg.

2014 Dec;12(12):1495-9. https://doi.org/10.1016/i.ijsu.2014.07.013

14. Goettems ML, Ardenghi TM, Romano AR, Demarco FF, Torriani DD. Influence of maternal dental anxiety on the child's dental caries experience. Caries Res. 2012;46(1):3-8. https://doi.org/10.1159/000334645

15. Boeira GF, Correa MB, Peres KG, Peres MA, Santos IS, Matijasevich A, et al. Caries is the main cause for dental pain in childhood: findings from a birth cohort. Caries Res. 2012;46(5):488-95. https://doi.org/10.1159/000339491

16. Alaluusua S, Malmivirta R. Early plaque accumulation: a sign for caries risk in young children. Community Dent Oral Epidemiol. 1994 Oct;22(5 Pt 1):273-6. https://doi.org/10.1111/j.1600-0528.1994.tb02049.x

17. Frencken J, Hilgert AS, Bronkhorst E, Leal S. Manual: caries assessment spectrum and treatment. Nijimegen: Department of Global Oral Health; 2015.

18. Ardenghi TM, Piovesan C, Antunes JL. [Inequalities in untreated dental caries prevalence in preschool children in Brazil]. Rev Saude Publica. 2013 Dec;47 Suppl 3:129-37. Portuguese. https://doi.org/10.1590/S0034-8910.2013047004352

19. Corrêa-Faria P, Paixão-Gonçalves S, Paiva SM, Pordeus IA. Incidence of dental caries in primary dentition and risk factors: a longitudinal study. Braz Oral Res. 2016 May;30(1):59. https://doi.org/10.1590/1807-3107BOR-2016.vol30.0059

20. Ministério da Saúde (BR). Secretaria de Atenção à Saúde. Secretaria de Vigilância em Saúde. SB Brasil 2010: Pesquisa Nacional de Saúde Bucal: resultados principais. Brasília, DF: Ministério da Saúde; 2011.

21. Pesaressi E, Villena RS, Frencken JE. Dental caries and oral health-related quality of life of 3-year-olds living in Lima, Peru. Int J Paediatr Dent. 2020 Jan;30(1):57-65. https://doi.org/10.1111/ipd.12582

22. Li Y, Zhang Y, Yang R, Zhang Q, Zou J, Kang D. Associations of social and behavioural factors with early childhood caries in Xiamen city in China. Int J Paediatr Dent. 2011 Mar;21(2):103-11. https://doi.org/10.1111/i.1365-263X.2010.01093.x

23. Folayan MO, Kolawole KA, Oziegbe EO, Oyedele T, Oshomoji OV, Chukwumah NM, et al. Prevalence, and early childhood caries risk indicators in preschool children in suburban Nigeria. BMC Oral Health. 2015 Jun;15(15):72. https://doi.org/10.1186/s12903-015-0058-y

24. Zhou N, Zhu H, Chen Y, Jiang W, Lin X, Tu Y, et al. Dental caries and associated factors in 3 to 5 -year-old children in Zhejiang Province, China: an epidemiological survey. BMC Oral Health. 2019 Jan;19(1):9. https://doi.org/10.1186/s12903-018-0698-9

25. Lynch RJ. The primary and mixed dentition, post-eruptive enamel maturation and dental caries: a review. Int Dent J. 2013 Dec;63 Suppl 2:3-13. https://doi.org/10.1111/idj.12074

26. Guedes RS, Piovesan C, Floriano I, Emmanuelli B, Braga MM, Ekstrand KR, et al. Risk of initial and moderate caries lesions in primary teeth to progress to dentine cavitation: a 2-year cohort study. Int J Paediatr Dent. 2016 Mar;26(2):116-24. https://doi.org/10.1111/ipd.12166

27. Marinho VC. Cochrane reviews of randomized trials of fluoride therapies for preventing dental caries. Eur Arch Paediatr Dent. 2009 Sep;10(3):183-91. https://doi.org/10.1007/BF03262681

28. Babaei A, Pakdaman A, Hessari H, Shamshiri AR. Oral health of 6-7 year-old children according to the Caries Assessment Spectrum and Treatment (CAST) index. BMC Oral Health. 2019 Jan;19(1):20. https://doi.org/10.1186/s12903-018-0709-x 